\title{
Taxanes during Pregnancy: Probably Safe, but Still to Be Optimized
}

\author{
Paul Berveiller Olivier Mir \\ CALG (Cancers Associés à La Grossesse) Network, Paris, France
}

Breast and other gynecological cancers are increasingly prevalent in pregnant women. As far as chemotherapy is concerned, drug selection is critical in this setting, with the aim to efficiently treat the mother without harming the developing fetus.

In the current issue of Oncology, Zagouri et al. [1] performed a systematic review regarding the use of taxanes in ovarian cancers occurring during pregnancy. This review suggests that taxanes (especially paclitaxel) might be used during the second and third trimesters of pregnancy in ovarian cancer patients with an acceptable safety profile. Moreover, data regarding the survival of mothers were reassuring as well.

Similarly, regarding the use of taxanes in breast cancer patients during pregnancy, a previous systematic review seemed to confirm these reassuring data [2]. Hence, these results led international experts to conclude that taxanes may be safely used during pregnancy in breast cancer patients [3].

It is noteworthy that pregnancy leads to important physiological and metabolic changes that may alter or interfere with the pharmacokinetics and pharmacodynamics of anticancer drugs [4]. These changes could lead to suboptimal plasma concentrations, even if common doses of cytotoxic drugs are used. For instance, an increase in distribution volume may lead to decreased plasma exposure. Additionally, an increase in glomerular filtration could likely lead to increased excretion. Moreover, amniotic fluid may act as a third space for many drugs, as recently documented for dasatinib [5]. Finally, the decrease in albumin level observed during pregnancy may favor the transplacental transfer rate of many drugs, especially highly protein-bound molecules [6].

To date, little is known about the optimal dosing regimen for taxanes in pregnant patients because clinical pharmacokinetic studies are scarce $[7,8]$. These data indicate that pregnant patients receiving paclitaxel had lower AUC and higher clearance compared to nonpregnant patients. Hence, this study suggested that conventional-dosing schedules may result in sub-optimal exposure. Besides, to date, no clinical data on docetaxel pharmacokinetics in pregnant women are available. Regarding the metabolism of taxanes, paclitaxel is mainly metabolized by cytochrome $\mathrm{P} 450$ (CYP) 2C8, and to a lesser extent by CYP3A4 [9]. On the other hand, docetaxel is mainly metabolized by CYP3A4. Importantly, CYP3A4 is a phase I enzyme with increasing activity (by $50-100 \%$ ) during the third trimester of pregnancy [10], putting pregnant patients at risk of sub-optimal exposure given the higher clearance.

\section{KARGER}

Fax +41613061234 E-Mail karger@karger.ch www.karger.com

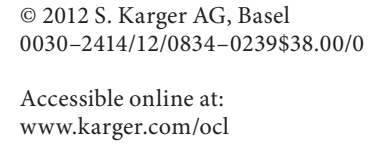

Department of Medical Oncology, Cochin Teaching Hospital

Université Paris Descartes, AP-HP

27, rue du faubourg Saint Jacques, FR-75014 Paris (France)

Tel. +33 15841 14 39, E-Mail olivier.mir@cch.aphp.fr 
Moreover, only ex vivo data are available on the transplacental transfer of taxanes in humans. In a human placental perfusion model, the transplacental transfer rate of paclitaxel was found to be low $(<5 \%)$ in a few previous studies [11, 12]. Only one report documented a comparative transplacental transfer of both taxanes, and failed to demonstrate any significant difference between paclitaxel and docetaxel [13]. Furthermore, taxanes are known to be substrates for a well-known drug transporter, the $\mathrm{P}$ glycoprotein (P-gp, MDR1, ABCB1) [14]. This placental transporter acts as an efflux pump, rejecting taxanes (and many others drugs) toward the maternal compartment. Hence, the P-gp plays a critical role in decreasing their tissular accumulation and subsequently in protecting the fetal organism [15].

In conclusion, as evidenced by Zagouri et al. [1] in gynecological cancers, current data converge to stress that taxanes might be used with a relatively safe short-term toxicity profile in pregnant patients. Due to their mecha- nism of action, taxanes should be preferably used rather than DNA-damaging agents such as etoposide or other alkylating agents, with unknown long-term consequences for the offspring, especially in terms of second malignancies.

However, due to pregnancy-associated pharmacokinetic changes, one could assume that the efficacy of taxanes might be limited in some cases. Hence, further clinical and pharmacokinetic investigations are mandatory in the forthcoming years in order to define the optimal drug dosing regimen for taxanes in pregnant patients.

\section{Disclosure Statement}

Dr. Mir has acted as advisory board member/consultant for Roche, Pfizer, and Servier. Dr. Berveiller has no conflict of interest to declare.

\section{References}

1 Zagouri F, Sergentanis TN, Chrysikos D, Filipits M, Bartsch R: Taxanes for ovarian cancer during pregnancy: a systematic review. Oncology 2012;83:234-238.

-2 Mir O, Berveiller P, Goffinet F, Treluyer JM, Serreau R, Goldwasser F, Rouzier R: Taxanes for breast cancer during pregnancy: a systematic review. Ann Oncol 2010;21:425-426.

-3 Amant F, Deckers S, Van Calsteren K, Loibl S, Halaska M, Brepoels L, Beijnen J, Cardoso F, Gentilini O, Lagae L, Mir O, Neven P, Ottevanger N, Pans S, Peccatori F, Rouzier R, Senn HJ, Struikmans H, Christiaens MR, Cameron D, Du Bois A: Breast cancer in pregnancy: recommendations of an international consensus meeting. Eur J Cancer 2010; 46:3158-3168.

4 Mir O, Berveiller P, Serreau R: Using anticancer agents during the post-partum period: not that simple. Onkologie 2010;33:419.

$\checkmark 5$ Berveiller P, Andreoli A, Mir O, Anselem O, Delezoide AL, Sauvageon H, Chapuis N, Tsatsaris V: A dramatic fetal outcome following transplacental transfer of dasatinib. Anticancer Drugs 2012;23:754-757.
-6 Berveiller P, Mir O, Vinot C, Bonati C, Duchene P, Giraud C, Gil S, Treluyer JM: Transplacental transfer of oseltamivir and its metabolite using the human perfused placental cotyledon model. Am J Obstet Gynecol 2012; 206:92.e1-6.

-7 Lycette JL, Dul CL, Munar M, Belle D, Chui SY, Koop DR, Nichols CR: Effect of pregnancy on the pharmacokinetics of paclitaxel: a case report. Clin Breast Cancer 2006;7:342344.

$>8$ Van Calsteren K, Verbesselt R, Ottevanger N, Halaska M, Heyns L, Van Bree R, de Bruijn E, Chai D, Delforge M, Noens L, Renard V, Witteveen E, Rob L, de Hoon J, Amant F: Pharmacokinetics of chemotherapeutic agents in pregnancy: a preclinical and clinical study. Acta Obstet Gynecol Scand 2010;89:1338-1345.

-9 Cresteil T, Monsarrat B, Alvinerie P, Treluyer JM, Vieira I, Wright M: Taxol metabolism by human liver microsomes: identification of cytochrome p450 isozymes involved in its biotransformation. Cancer Res 1994;54: 386-392.

-10 Anderson GD: Pregnancy-induced changes in pharmacokinetics: a mechanistic-based approach. Clin Pharmacokinet 2005;44: 989-1008.
11 Nekhayeva IA, Nanovskaya TN, Hankins GD, Ahmed MS: Role of human placental efflux transporter P-glycoprotein in the transfer of buprenorphine, levo-alpha-acetylmethadol, and paclitaxel. Am J Perinatol 2006;23:423-430.

12 Nanovskaya T, Nekhayeva I, Karunaratne N, Audus K, Hankins GD, Ahmed MS: Role of P-glycoprotein in transplacental transfer of methadone. Biochem Pharmacol 2005;69: 1869-1878.

13 Berveiller P, Gil S, Mir O, Vinot C, Urien S, Chissey A, Simasotchi C, Tsatsaris V, Treluyer J: Taxanes for treatment of cancer occurring during pregnancy: Study of placental transfers of paclitaxel and docetaxel with the ex vivo perfused human cotyledon model. Fundam Clin Pharmacol 2011;25:36.

$>14$ Nagashige M, Ushigome F, Koyabu N, Hirata K, Kawabuchi M, Hirakawa T, Satoh S, Tsukimori K, Nakano H, Uchiumi T, Kuwano M, Ohtani H, Sawada Y: Basal membrane localization of MRP1 in human placental trophoblast. Placenta 2003;24:951-958.

15 Fromm MF: Importance of P-glycoprotein at blood-tissue barriers. Trends Pharmacol Sci 2004;25:423-429. 